\title{
Root-Specific Role for Nicotiana benthamiana RDR6 in the Inhibition of Chinese wheat mosaic virus Accumulation at Higher Temperatures
}

\author{
Ida Bagus Andika, ${ }^{1}$ Liying Sun, ${ }^{1}$ Rong Xiang, ${ }^{2}$ Junmin Li, ${ }^{1}$ and Jianping Chen ${ }^{1}$ \\ ${ }^{1}$ State Key Laboratory Breeding Base for Zhejiang Sustainable Pest and Disease Control, Ministry of Agriculture Key \\ Laboratory of Biotechnology in Plant Protection, Institute of Virology and Biotechnology, Zhejiang Academy of Agricultural \\ Sciences, Hangzhou 310021, P. R. China; ${ }^{2}$ College of Chemistry and Life Science, Zhejiang Normal University, Jinhua \\ 321004, China
}

Submitted 15 May 2013. Accepted 10 June 2013.

\begin{abstract}
Some viruses only infect plants at cool temperatures but the molecular mechanism underlying this low-temperature dependence remains unclear. Chinese wheat mosaic virus (CWMV, genus Furovirus) was able to infect wheat and Nicotiana benthamiana plants at 16 but not at $24^{\circ} \mathrm{C}$. When CWMV-infected plants were transferred to $24^{\circ} \mathrm{C}$ for 2 weeks, the newly emerged leaves and roots became virus free. Co-infection with Potato virus $Y$ rescued CWMV accumulation in $N$. benthamiana plants after a temperature shift to $24^{\circ} \mathrm{C}$. In transgenic $N$. benthamiana plants silenced for the $N$. benthamiana $R N A$-dependent $R N A$ polymerase 6 (NbRDR6), CWMV was able to accumulate in roots but not in leaves after a temperature shift to $24^{\circ} \mathrm{C}$. Deep sequencing of small RNAs showed that, at $16^{\circ} \mathrm{C}$, abundant CWMV small interfering (si)RNAs accumulated in infected $N$. benthamiana plants. Silencing of NbRDR6 increased the abundance of CWMV siRNAs and the generation of siRNAs from hotspots in the CWMV genome. In contrast, when shifted to $24^{\circ} \mathrm{C}$ for 1 week, CWMV siRNAs were markedly fewer in roots of $N b R D R 6$-silenced than in roots of wildtype plants but were similar in the leaves of those plants. Our results demonstrate the root-specific role of NbRDR6 in the inhibition of CWMV accumulation and biogenesis of CWMV siRNAs at higher temperatures.
\end{abstract}

The establishment of viruses in plants is greatly affected by environmental factors, particularly by temperature (Garrett et al. 2006; Hull 2002). Temperature may affect viral infection either because a specific temperature range is required for optimal virus replication in cells (Mizumoto et al. 2002; Ohsato et al. 2003; Roossinck 1991) or indirectly through the regulation of the host antiviral defense responses (Kassanis 1952; Szittya et al. 2003; Wang et al. 2009; Zhang et al. 2012). Numerous studies have demonstrated that the optimal temperature required for virus infection in plants varies depending

Corresponding authors: L. Sun; E-mail: sunly_de@126.com; Telephone: +86(571) 8641-9021; Fax: +86(571) 8640-4258; and J. Chen; E-mail: jpchen2001@yahoo.com.cn; Telephone: +86(571) 8640-4003; Fax: +86(571) 8640-4258.

* The $e$-Xtra logo stands for "electronic extra" and indicates that four supplementary figures and one supplementary table are published online and that Figures 1, 2, 5, 6, 7, and 8 appear in color online.

(C) 2013 The American Phytopathological Society upon specific virus-host combinations (Liu et al. 2009). The majority of plant viruses are able to infect plants at ambient temperatures $\left(20\right.$ to $25^{\circ} \mathrm{C}$ ) (Hull 2002) but some viruses only infect plants under cool conditions (below $20^{\circ} \mathrm{C}$ ). For example, viruses belonging to the genera Furovirus (family Virgaviridae) and Bymovirus (family Potyviridae) infect winter cereal crops (Kühne 2009). The infected plants usually show conspicuous yellow mosaic symptoms during spring but, when the temperature increases during early summer, the newly developed leaves become virus free (Brunt and Richards 1989). The reason for the low-temperature dependence is not well understood but a study using barley protoplasts showed that the optimal temperature for replication of Soil-borne wheat mosaic virus (SBWMV, genus Furovirus) was $17^{\circ} \mathrm{C}$ (Ohsato et al. 2003).

RNA silencing downregulates the gene expression of cellular organisms by targeting endogenous or exogenous RNAs in a sequence-specific manner, and plays a crucial role in antiviral defense through such activities (Baulcombe 2005; Chang et al. 2012; Merkling and van Rij 2012). In plants, this antiviral defense operates to reduce viral RNA levels in the infected cells or limit viral cell-to-cell and long-distance movement (Deleris et al. 2006; Diaz-Pendon et al. 2007). RNA silencing is triggered by double-stranded RNA (dsRNA) molecules that are derived from viral RNA replicative intermediates, highly structured viral single-stranded RNA (ssRNA), overlapping transcripts of DNA viruses, or by synthesis of complementary strands of viral RNA by a cellular RNA-dependent RNA polymerase (RDR) (Ding 2010; Qu 2010; Wang et al. 2010). These dsRNA molecules are cleaved by an RNase-III enzyme called Dicer-like protein (DCL) into duplexes of small interfering RNAs (siRNAs) approximately 21 to 24 nucleotides (nt) long that are then incorporated into Argonaute protein (AGO)-containing RNA-induced silencing complexes (RISCs) that guide the slicing of complementary viral RNAs (Aliyari and Ding 2009). In Arabidopsis plants, 21-, 22- and 24-nt siRNAs are generated by DCL4, DCL2, and DCL3, respectively (Aliyari and Ding 2009; Ding 2010). In plants and other organisms, amplification of siRNAs by the activities of cellular RDR is required to further intensify the effect of RNA silencing (Voinnet 2008; Wang et al. 2010). It is known that RNA-silencing activities in plants are regulated by temperature (Kalantidis et al. 2002; Szittya et al. 2003). Below $20^{\circ} \mathrm{C}$, generation of viral siRNA is inhibited and, consequently, plants become more susceptible to the viruses (Chellappan et al. 2005; Szittya et al. 2003; Zhang et al. 2012). 
Studies using diverse plant species have similarly established an important role for plant-encoded RDR in antiviral defense. The expression of Nicotiana tabacum RDRl is induced by virus infection, and downregulation of RDRl results in increased accumulation of Tobacco mosaic virus (TMV) and allows systemic spread of Potato virus $X$ (PVX), a virus that is restricted in inoculated leaves of wild-type tobacco (Xie et al. 2001). Silencing of $N$. benthamiana RDR6 (NbRDR6) increases the susceptibility of $N$. benthamiana plants to several RNA viruses and permits the invasion of PVX, TMV, and Potato spindle tuber viroid (PSTVd) into meristem tissue (Di Serio et al. 2010; $\mathrm{Qu}$ et al. 2005; Schwach et al. 2005). Interestingly, NbRDR6 activity in antiviral defense is more pronounced at higher temperatures ( $\mathrm{Qu}$ et al. 2005), which further demonstrates the stimulating effect of higher temperature on RNA-silencing activity. Likewise, silencing of the rice $R D R 6$ enhances viral RNA accumulation and symptom expression of Rice stripe virus (RSV) (Jiang et al. 2012). The rdr6 mutant plants of Arabidopsis develop more severe symptoms than wild-type plants when infected with Cucumber mosaic virus (CMV) (Mourrain et al. 2000) while genome accumulation of a CMV mutant defective in its RNA-silencing suppressor is drastically elevated in rdr6 mutant plants (Wang et al. 2011).

Chinese wheat mosaic virus (CWMV) infects winter wheat plants in China and causes yellow mosaic disease (Kühne 2009). CWMV belong to the genus Furovirus and, like other members of this genus, is naturally transmitted by a root-infecting fungus-like organism, Polymyxa graminis (order Plasmodiophorales) (Brunt and Richards 1989; Diao et al. 1999). Its genome consists of two positive-sense ssRNAs, which are encapsidated in rod-shaped particles. The larger RNA (RNA 1) encodes three proteins, two of which are required for viral replication, while the other $(37 \mathrm{kDa})$ functions as a viral movement protein. RNA 2 encodes a 19-kDa major coat protein (CP), a minor CP readthrough protein of $84 \mathrm{kDa}$, and a $19-\mathrm{kDa}$ small cysteine-rich RNA-silencing suppressor (Andika et al. 2013; Diao et al. 1999; Sun et al. 2013)

This study aimed to investigate the underlying mechanism for the low-temperature dependence of CWMV infection. For this purpose, $N$. benthamiana plants were co-infected with CWMV and Potato virus $Y$ (PVY) and examined for altered disease development under different temperature conditions. In addition, transgenic $N$. benthamiana plants silenced for NbRDR6 were compared with wild-type $N$. benthamiana to reveal potential temperature-dependent susceptibility changes. Finally, the profiles of CWMV-derived siRNAs at low and higher temperatures were comprehensively analyzed by deep sequencing of small RNAs. Collectively, the results support the notion that the RNA-silencing pathway is involved in the inhibition of CWMV multiplication at higher temperatures.

\section{RESULTS}

CWMV systemic infection in wheat and $N$. benthamiana requires cool conditions.

To examine the effect of temperature on CWMV infection, wheat plants were mechanically inoculated with CWMV and kept at 16 or $24^{\circ} \mathrm{C}$. Starting from 4 weeks postinoculation (wpi), the upper leaves of plants kept at $16^{\circ} \mathrm{C}$ developed mild chlorotic symptoms but there was no effect on plant growth and morphology compared with noninoculated wheat plants (Fig. 1A, leaf-inoculated, $16^{\circ} \mathrm{C}$ ). Symptom severity was clearly milder than that on naturally infected (root-inoculated) wheat plants in the fields, where conspicuous yellow stripes with slight necrosis on leaves and plant stunting were observed (Fig. 1A, root-inoculated). The inoculated wheat plants that were kept at $24^{\circ} \mathrm{C}$ did not develop any symptoms (Fig. 1A, leaf-inoculated, $\left.24^{\circ} \mathrm{C}\right)$. $N$. benthamiana is known to be susceptible to a wide range of plant viruses and is commonly used as an experimental host for virological studies (Goodin et al. 2008). CWMV

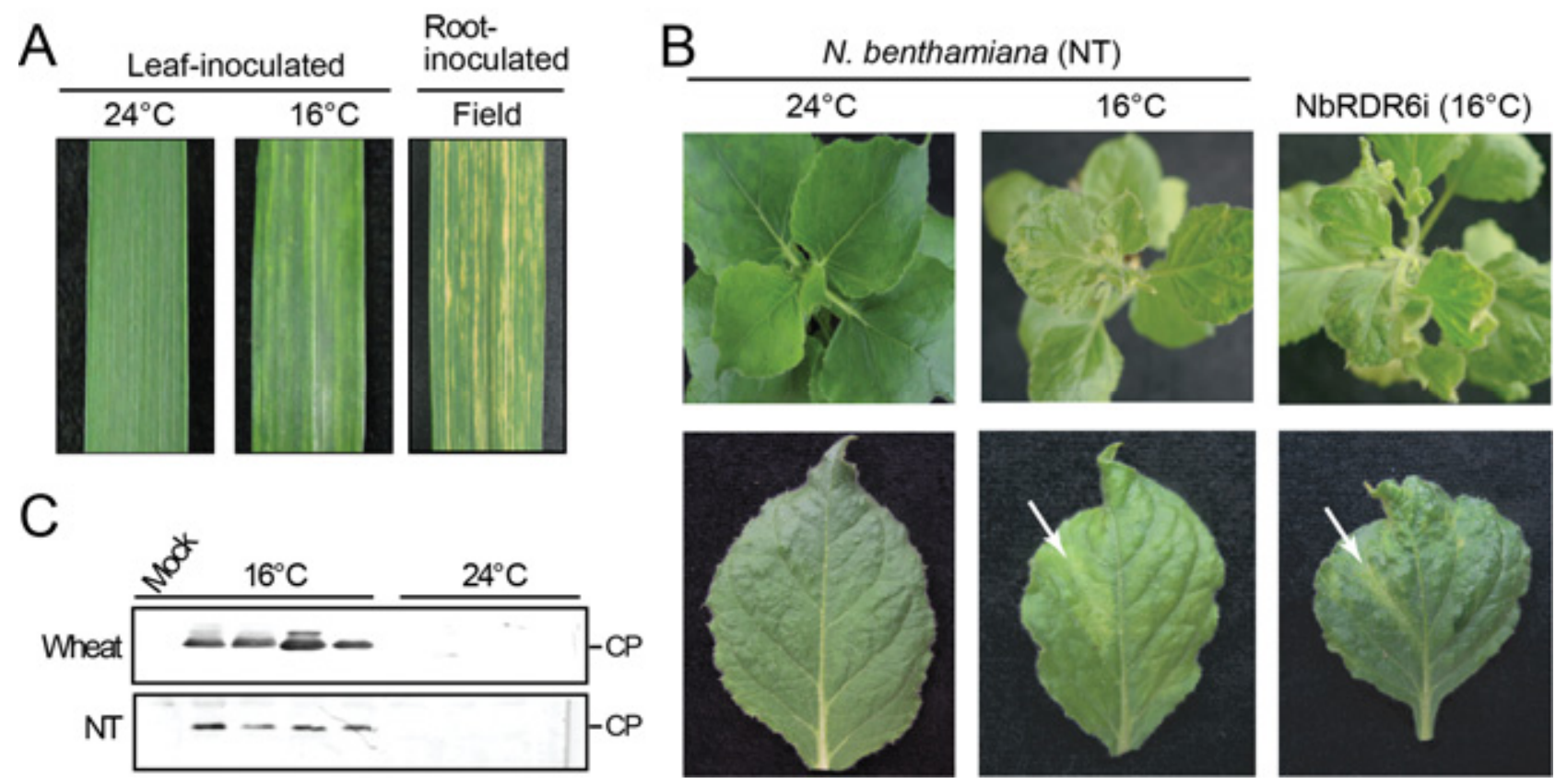

Fig. 1. Effect of temperature on Chinese wheat mosaic virus (CWMV) infection in wheat and Nicotiana benthamiana plants. A, Development of viral symptoms in upper leaves of wheat plants that were infected naturally with CWMV through its fungal-like vector in the field (root-inoculated) or mechanically inoculated with CWMV and kept at 16 or $24^{\circ} \mathrm{C}$. Upper leaves of mechanically inoculated plants were photographed at 5 weeks postinoculation (wpi). B, Viral symptom expression in the upper systemic leaves of nontransgenic $N$. benthamiana (NT) and transgenic N. benthamiana plants silenced for RNA-dependent RNA polymerase 6 (NbRDR6i) that had been mechanically inoculated with CWMV and grown at 24 or $16^{\circ} \mathrm{C}$. Plants were photographed at 6 wpi. Arrows mark the yellow patches on the leaves. C, Western blot analysis of CWMV coat protein (CP) accumulation in upper leaves of wheat and $N$. benthamiana (NT) plants inoculated with CWMV and grown at 16 or $24^{\circ} \mathrm{C}$. Leaves were sampled at 6 wpi. Each lane represents the protein sample from a single plant. rovide an explanation for this observat 
was next inoculated onto leaves of $N$. benthamiana plants which were then kept at 16 or $24^{\circ} \mathrm{C}$. Starting from 5 wpi, the upper leaves of plants kept at $16^{\circ} \mathrm{C}$ but not those kept at $24^{\circ} \mathrm{C}$ developed light yellow patches or chlorosis (Fig. 1B, NT). The newly developed leaves were slightly wrinkled or deformed but no plant stunting was observed (Fig. $1 \mathrm{~B}, \mathrm{NT}, 16^{\circ} \mathrm{C}$ ). At 6 wpi, Western blot analysis using an antibody specific for CWMV CP detected CWMV accumulation in upper systemic leaves of wheat and $N$. benthamiana plants kept at $16^{\circ} \mathrm{C}$ but not in leaves of plants kept at $24^{\circ} \mathrm{C}$ (Fig. 1C).

Next, we did a temperature shift experiment in which symptomatic CWMV-infected wheat and $N$. benthamiana plants previously grown at $16^{\circ} \mathrm{C}$ for 6 weeks were placed at $24^{\circ} \mathrm{C}$ and symptoms and virus accumulation were monitored. After the temperature was shifted to $24^{\circ} \mathrm{C}$, newly emerged leaves of $N$. benthamiana and wheat were symptom free (Fig. 2A, CWMV; data not shown for wheat plants). At 1 and 2 weeks after the temperature shift, no CWMV CP could be detected by Western blot analysis in the upper leaves or roots of wheat plants (Fig.
2B, wheat, TS lane). In $N$. benthamiana plants 1 week after the temperature shift, CWMV CP could be detected by Western blotting in roots but not in leaves (Fig. 2B, NT at 1 week, TS lane), while CWMV RNA2 could be detected by reverse-transcription-polymerase chain reaction (RT-PCR) in both leaves and roots, although the amount of CWMV RNA2 in leaves was very low (data not shown). One week later, CWMV CP and RNA2 could not be detected in either tissue by Western blotting and RT-PCR (Fig. 2B, NT at 2 weeks, TS lane; D, CWMV, TS lane). Together, these observations demonstrate that CWMV infection requires a low temperature in both its natural and experimental hosts.

\section{Co-infection with PVY rescues CWMV accumulation at higher temperatures.}

A synergistic effect in mixed infections of plant viruses often results in increased disease severity and virus accumulation or breakdown of host plant resistance (García-Cano et al. 2006; Syller 2012). Viruses that belong to the genus Potyvirus

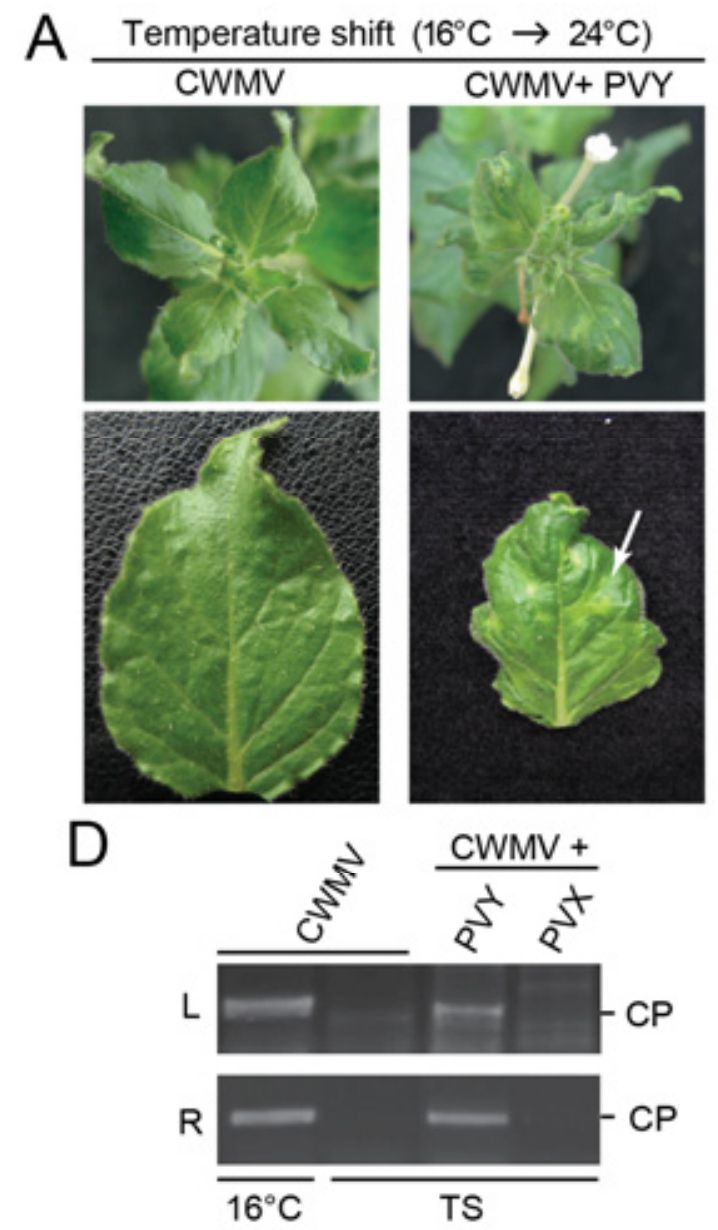

$\mathrm{L}=$ leaves $\mathrm{R}=$ roots
B

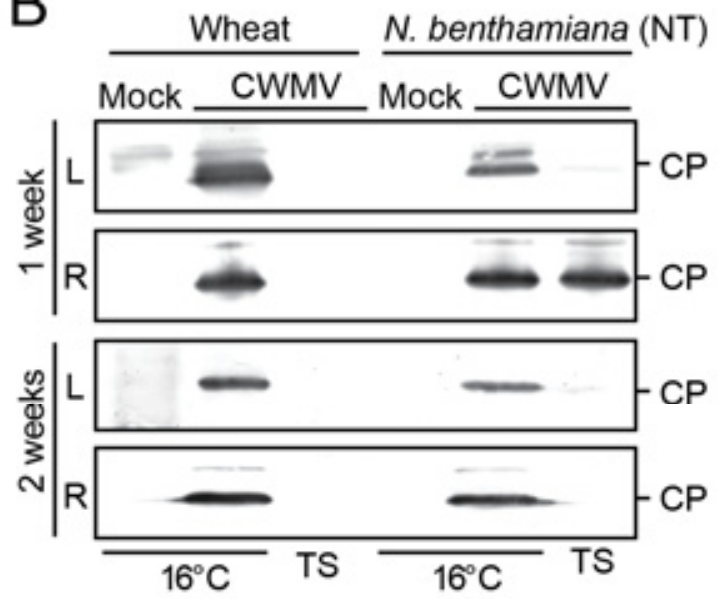

C

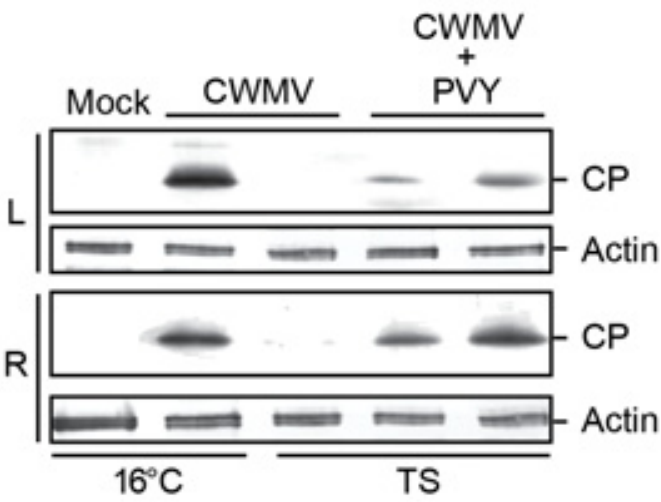

TS $=$ Temperature shift

Fig. 2. Effect of co-infection with Potato virus $Y$ (PVY) on Chinese wheat mosaic virus (CWMV) accumulation at a higher temperature. A, Viral symptom expression in the upper leaves of a CWMV-infected nontransgenic Nicotiana benthamiana (NT) plant that was previously grown at $16^{\circ} \mathrm{C}$ for 6 weeks and then kept at $24^{\circ} \mathrm{C}$ for 2 weeks (left image) or a CWMV-infected plant that had similar treatment but was co-inoculated with PVY (right image). An arrow marks the yellow patch on the leaf. B, Western blot analysis of CWMV coat protein (CP) accumulation in infected wheat and NT plants that were previously grown at $16^{\circ} \mathrm{C}$ for 6 weeks and then kept at $24^{\circ} \mathrm{C}$. Upper leaves (L) and roots (R) of infected plants were sampled at 1 and 2 weeks after temperature shift (TS) to $24^{\circ} \mathrm{C}$ or at 8 weeks postinoculation for those grown throughout at $16^{\circ} \mathrm{C}$. Each lane represents the protein sample pooled from three plants. C, Western blot analysis of CWMV CP accumulation in upper leaves and roots of CWMV-infected NT plants co-inoculated with PVY and then kept at $24^{\circ} \mathrm{C}$ for 2 weeks. Each lane represents the protein sample from a single plant. Detection of $\beta$-actin (approximately $85 \mathrm{kDa}$ ) serves as a loading control. D, Reversetranscription-polymerase chain reaction (PCR) detection of CWMV RNA2 accumulation in upper leaves and roots of CWMV-infected NT plants co-inoculated with PVY or Potato virus $X(\mathrm{PVX})$ and then kept at $24^{\circ} \mathrm{C}$ for 2 weeks (TS). CWMV CP-specific primers were used for PCR amplification. Each lane represents the RNA sample pooled from two plants. The length of PCR products is $531 \mathrm{bp}$. 
are known to enhance viral accumulation or replication of unrelated viruses in co-infection experiments, because of the suppression of RNA-silencing-mediated defense by the helper component proteinase (HC-Pro)-silencing suppressor encoded by potyviruses (Pruss et al. 1997; Shi et al. 1997; Vance et al. 1995). We hypothesized that, if RNA silencing is responsible for suppression of CWMV multiplication, co-infection with a potyvirus might enable CWMV accumulation at $24^{\circ} \mathrm{C}$. To assess this possibility, CWMV-infected $N$. benthamiana plants that were previously grown at $16^{\circ} \mathrm{C}$ for 6 weeks after inoculation were mechanically inoculated with PVY (genus Potyvirus) and then kept at $24^{\circ} \mathrm{C}$. Starting from 6 to 8 days after inoculation of PVY, the plants showed typical PVY symptoms in their upper leaves such as yellow patches accompanied with strong leaf crinkle or malformation of the leaves (Fig. 2A, CWMV+PVY). These symptoms were similar to those caused
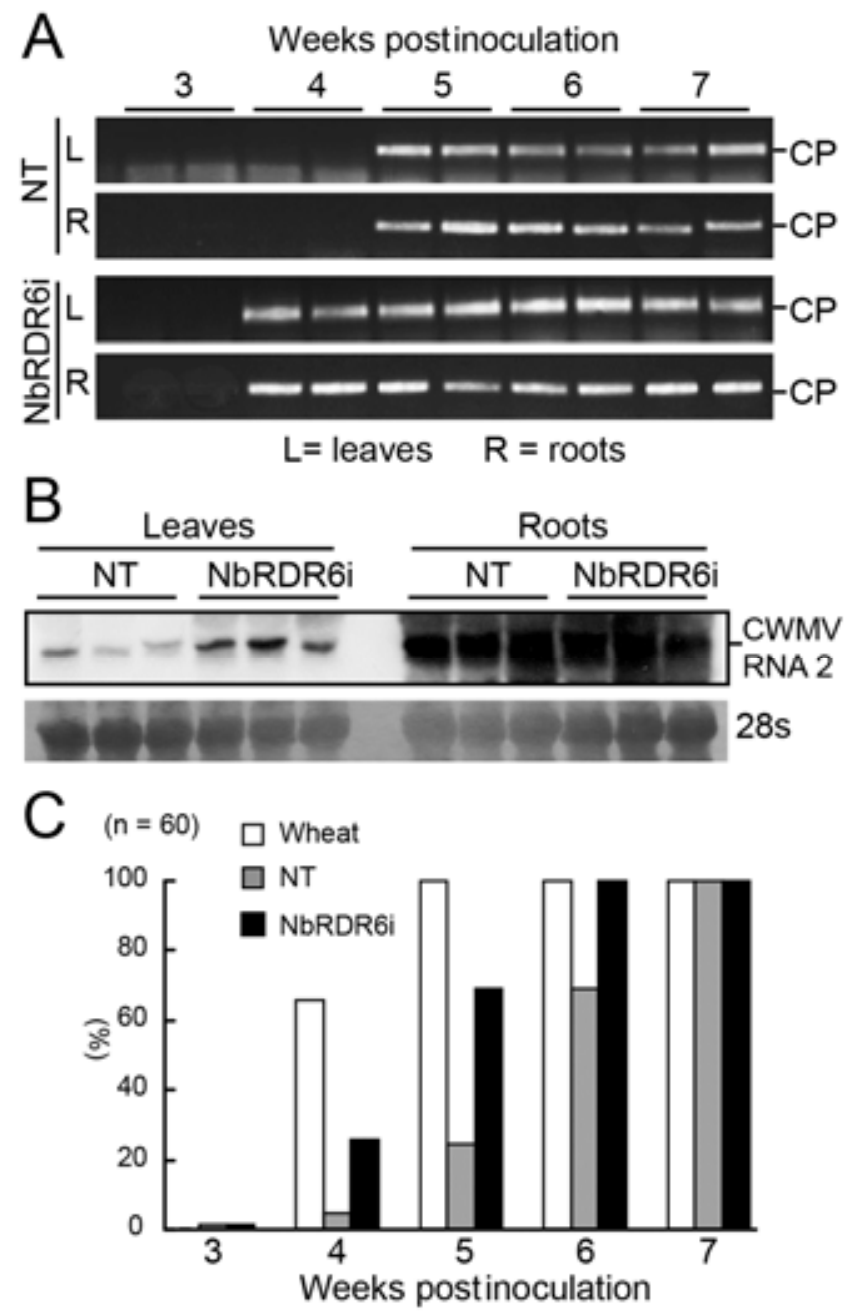

Fig. 3. Effect of silencing of Nicotiana benthamiana RNA-dependent RNA polymerase 6 (NbRDR6) on accumulation and systemic spread of Chinese wheat mosaic virus (CWMV) at $16^{\circ} \mathrm{C}$. A, Reverse-transcriptionpolymerase chain reaction detection of CWMV RNA2 in upper leaves (L) and roots (R) of nontransgenic $N$. benthamiana plants (NT) and transgenic $N$. benthamiana plants silenced for NbRDR6 (NbRDR6i) 3 to 7 weeks postinoculation (wpi). Each lane represents the RNA sample from a single plant. B, Northern blot analysis of CWMV RNA2 accumulation in upper leaves and roots of NT and NbRDR6i plants grown at $16^{\circ} \mathrm{C}$. Total RNAs were extracted from leaves and roots at 6 wpi. The membrane was stained with methylene blue and 28S rRNA is shown as a loading control (lower panel). Each lane represents the RNA sample from a single plant. C, Percentage of systemically infected wheat, NT, and NbRDR6i plants from 3 to 7 wpi. Enzyme-linked immunosorbent assay was used to detect CWMV in the upper leaves. by PVY alone (data not shown). Two weeks after the temperature shift to $24^{\circ} \mathrm{C}$, CWMV CP accumulation was detected by Western blotting in leaves and roots of plants co-infected with PVY but not in plants that were not inoculated with PVY (Fig. 2C, compare CWMV+PVY with CWMV, TS lane). In addition, RT-PCR confirmed the presence of CWMV RNA2 in leaves and roots of co-infected plants (Fig. 2D, CWMV+PVY). These results show that PVY infection rescues CWMV accumulation at $24^{\circ} \mathrm{C}$. CWMV CP accumulation detected in leaves of co-infected plants was much less than in leaves of the plants kept at $16^{\circ} \mathrm{C}$ whereas comparable levels of $\mathrm{CP}$ accumulation were detected in the roots of those plants (Fig. 2C, compare $\mathrm{CWMV}+\mathrm{PVY}$, TS lane with $\mathrm{CWMV}, 16^{\circ} \mathrm{C}$ lane), indicating that PVY infection has only a partial effect in rescuing CWMV accumulation in leaves. In a parallel experiment when CWMVinfected plants were inoculated with PVX (genus Potexvirus), CWMV accumulation was not detected in leaves and roots of co-infected plants by RT-PCR (Fig. 2D, CWMV+PVX).

\section{Silencing of $N b R D R 6$ enhances RNA accumulation and systemic movement of CWMV.}

In the next experiment, we used transgenic $N$. benthamiana plants carrying an RNAi hairpin construct for silencing of NbRDR6 (NbRDR6i) (Schwach et al. 2005). In all, 20 NbRDR6i plants were mechanically inoculated with CWMV; then, 10 plants were kept at $16^{\circ} \mathrm{C}$ and the other 10 plants at $24^{\circ} \mathrm{C}$. At 4 wpi, upper leaves of 3 of 10 plants at $16^{\circ} \mathrm{C}$ showed chlorosis, whereas all nontransgenic (NT) $N$. benthamiana plants remained symptomless. RT-PCR analysis confirmed the presence of CWMV RNA2 in the upper leaves and roots of symptomatic NbRDR6i plants from 4 wpi but not in NT plants, where viral symptoms appeared and CWMV RNA2 was detected from 5 wpi (Fig. 3A). By contrast, viral symptoms and virus accumulation were not detected until $7 \mathrm{wpi}$ in upper leaves of NbRDR6i plants kept at $24^{\circ} \mathrm{C}$ (data not shown), indicating that silencing of NbRDR6 does not permit CWMV infection of stems and leaves at a higher temperature. NbRDR6i plants developed slightly more severe symptoms than the NT controls, with more conspicuous yellow patches interspersed with green areas on the upper leaves. In addition, the leaves also showed stronger wrinkling (Fig. 1B, compare NbRDR6i with NT at $16^{\circ} \mathrm{C}$ ). Northern blot analysis showed that, at 6 wpi, CWMV RNA2 accumulations were greater in leaves of NbRDR6i plants than in leaves of NT plants but were similar in the roots of these plants (Fig. 3B). Strikingly, CWMV RNA2 accumulated much more in roots than leaves of both plants (Fig. 3B).

To further examine the effect of silencing of NbRDR6 on CWMV systemic spread at $16^{\circ} \mathrm{C}$, a large number of NT and NbRDR6i plants (60 plants of each) were inoculated with CWMV and the presence of CWMV in upper leaves was detected by enzyme-linked immunosorbent assay (ELISA). As a comparison, CWMV was also inoculated into wheat plants. At 4, 5, and 6 wpi, markedly higher proportions of NbRDR6i than NT plants were systemically infected with CWMV (Fig. 3C). CWMV systemic spread appeared to be more efficient in wheat than in $N$. benthamiana. At 4 wpi, CWMV was readily detected in upper leaves of more than $60 \%$ of wheat plants and, at $5 \mathrm{wpi}$, all plants contained CWMV (Fig. 3C). This result indicates that NbRDR6 participates in the inhibition of CWMV systemic spread in $N$. benthamiana.

\section{Silencing of $N b R D R 6$ enables CWMV accumulation} in roots but not in leaves at a higher temperature.

To examine the effect of downregulation of NbRDR6 on CWMV accumulation at the higher temperature, CWMVinfected NbRDR6i plants were transferred to $24^{\circ} \mathrm{C}$ and symp- 
tom appearance and virus accumulation were monitored. As in the CWMV-infected NT plants, the newly emerged leaves were symptom free after the temperature shift (data not shown). Interestingly, 2 weeks after the temperature shift, CWMV CP was not detected in asymptomatic upper leaves but remained at high levels in the roots of NbRDR6i plants (Fig. 4A, NbRDR6i, TS lane). In a parallel experiment, CWMV CP was not detected in either asymptomatic upper leaves or the roots of NT plants (Fig. 4A, NT, TS lane). RT-PCR detection further confirmed the presence of CWMV RNA2 in roots but not in leaves of NbRDR6i plants (Fig. 4B). This result indicates that, at the higher temperature, NbRDR6 has an important role in the suppression of CWMV accumulation in roots.

\section{Biogenesis of CWMV siRNAs in roots} at higher temperatures requires NbRDR6.

To further gain insight into the role of RNA silencing in inhibition of CWMV accumulation, CWMV-derived siRNAs were analyzed by deep sequencing of small RNAs. Twelve small RNA cDNA libraries were generated using total RNA fractions extracted from the samples. These samples were either from the upper leaves $(\mathrm{L})$ or roots $(\mathrm{R})$ and were derived from CWMV-infected $N$. benthamiana NT, CWMV-infected NbRDR6i (R6), or noninfected $N$. benthamiana $(\mathrm{H})$ plants that were either grown continuously at $16^{\circ} \mathrm{C}$ for 6 weeks (16C) or were shifted from 16 to $24^{\circ} \mathrm{C}$ (24C) for 1 week. The 1 week temperature shift was chosen because, at this time, CWMV has not completely disappeared from upper leaves and roots (Fig. 2A and description in the text) and, therefore, we assumed that RNA substrates for viral siRNA production would still be available. For each library, total RNA was extracted from pooled leaves or roots of three plants. Sequencing of the small RNA cDNA libraries produced roughly 4 to 16 million raw reads for each library. Computational analyses were carried out to search for the presence of CWMV-derived siRNAs in each library, allowing for one mismatch to the virus reference sequence. A large number of small RNAs from the NT-L/16C, NT-R/16C, R6-L/16C, R6-R/16C, NT-R/24C, and R6-R/24C libraries matched the CWMV genome but fewer were found in the NT-L/24C and R6-L/24C libraries. This is likely due to the low levels of CWMV RNA accumulation in leaves of plants that had undergone temperature shift treatment to $24^{\circ} \mathrm{C}$. In contrast, very small numbers of small RNAs from the $\mathrm{H}$ L/16C, H-R/16C, H-L/24C, and H-R/24C libraries matched the CWMV genome, confirming that most of the matched small RNAs are, indeed, derived from viral sequences (Supplementary Table S1).

Normalization of read numbers of CWMV siRNAs with the total reads of the corresponding libraries revealed that CWMV siRNAs were much more abundant in the R6-L/16C and R6$\mathrm{R} / 16 \mathrm{C}$ libraries than in the NT-L/16C and NT-R/16C libraries (Fig. 5A), suggesting that, at low temperatures, silencing of NbRDR6 increases CWMV siRNA accumulation in both leaves and roots. On the other hand, viral siRNAs were equally frequent in the NT-L/24C and R6-L/24C libraries and they were slightly less in the R6-R/24C than in the NT-R/24C library (Fig. 5A). CWMV siRNAs were predominantly 21 and 22 nt long, with 21 nt being most abundant in all of the libraries (Fig. 5C and D). Interestingly, in the R6-R/24C library, 21- and 22-nt viral siRNAs were only slightly more abundant than the othersized viral siRNAs (Fig. 5D). Thus, the abundance of 21- and 22-nt viral siRNAs in the R6-R/24C library was significantly lower than in the NT-R/24C library whereas the 23- to 28-nt viral siRNAs were similar in the two libraries (Fig. 5D). This result indicates that, at the higher temperature, NbRDR6 plays an important role in biogenesis of CWMV siRNAs in roots but not in leaves. The 21- and 22-nt viral siRNAs produced by
DCL4 and DCL2, respectively, are crucial in antiviral defense against RNA viruses (Ding 2010). Therefore, this observation is in agreement with the finding that silencing of NbRDR6 enables CWMV to accumulate in roots at the higher temperature (Fig. 4). There were many NbRDR6 transgene-derived siRNAs in the R6-L/16C, R6-R/16C, R6-L/24C, and R6-R/24C libraries but not in other libraries. NbRDR6 transgene siRNAs were more abundant in the R6-L/16C than in the R6-L/24C library and also more in the R6-R/16C than the R6-R/24C library (Supplementary Fig. S1). The reason for this difference is unclear.

The proportions of CWMV antisense siRNA were similar in the NT-L/16C and R6-L/16C libraries and also in the NT$\mathrm{L} / 24 \mathrm{C}$ and R6-L/24C libraries while they were slightly higher in the R6-R/16C than in the NT-R/16C library (Fig. 5B). The proportions of CWMV antisense siRNA in the R6-R/24C and NT-R/24C libraries were relatively lower than those in other libraries and the R6-R/24C library had the least proportion of antisense siRNAs (Fig. 5B). Indeed, the R6-R/24C library had a much greater decrease in abundance of antisense $(64.1 \%)$ than sense $(24.8 \%)$ viral siRNAs, relative to those in the NT$\mathrm{R} / 24 \mathrm{C}$ library. The ratio of sense/antisense 21 - and 22-nt siRNAs increased from 1.75 in the NT-R/24C library to 2.87 in the R6-R/24C library. Thus, silencing of NbRDR6 markedly enhances the CWMV siRNA bias toward sense strand in roots. This observation is consistent with the proposed role of plant RDR in the synthesis of viral dsRNAs that are processed by
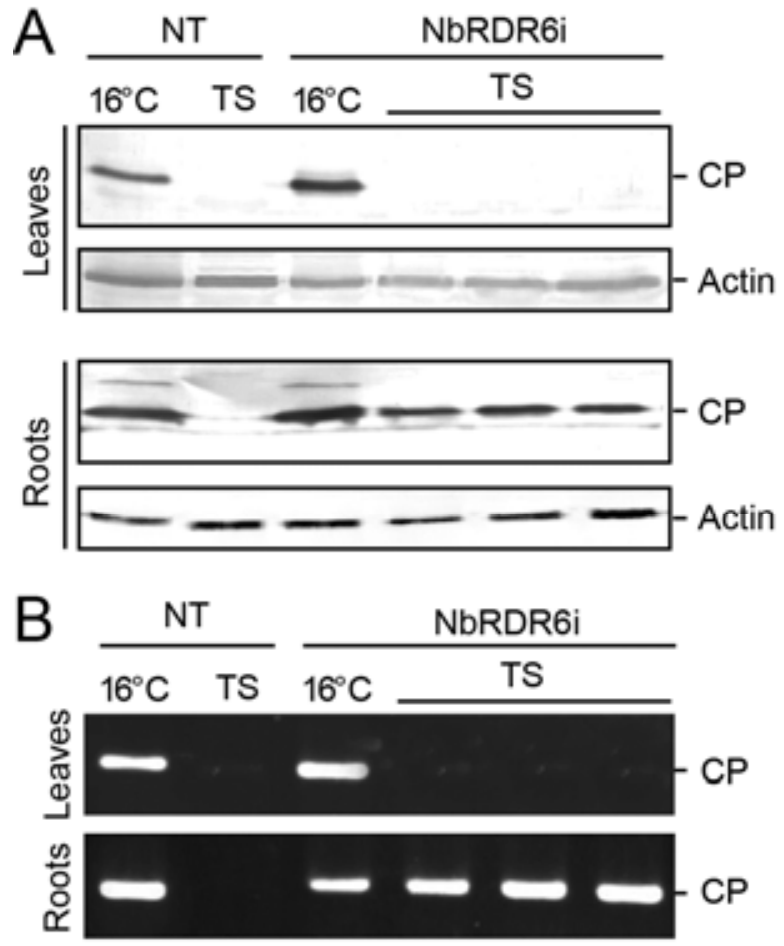

$$
\mathrm{TS}=\text { Temperature shift }\left(16^{\circ} \mathrm{C} \rightarrow 24^{\circ} \mathrm{C}\right)
$$

Fig. 4. Effect of silencing of Nicotiana benthamiana RNA-dependent RNA polymerase 6 (NbRDR6) on Chinese wheat mosaic virus (CWMV) accumulation at higher temperatures. A, Western blot analysis of CWMV coat protein (CP) accumulation in upper leaves and roots of CWMV-infected nontransgenic $N$. benthamiana plants (NT) and transgenic $N$. benthamiana plants silenced for NbRDR6 (NbRDR6i) that were grown throughout at $16^{\circ} \mathrm{C}$ for 8 weeks or previously grown at $16^{\circ} \mathrm{C}$ for 6 weeks and were then kept at $24^{\circ} \mathrm{C}$ for 2 weeks (TS). Detection of $\beta$-actin (approximately 85 $\mathrm{kDa}$ ) serves as a loading control. Each lane represents the protein sample from a single plant. B, Reverse-transcription-polymerase chain reaction detection of CWMV RNA2 in upper leaves and roots of plants described above. 
DCL into viral siRNAs (Ding 2010). All of the libraries had a similar distribution of the $5^{\prime}$-terminal nucleotide of CWMV siRNAs, with U being the most frequent (Fig. 6). However, the percentage of siRNAs with a $5^{\prime}$-terminal $U$ was markedly higher in the NT-L/24C than in the NT-L/16C library and also in the NT-R/24C than in the NT-R/16C library (Fig. 6A); however, less or no difference was observed between the R6-L/24C and R6-L/16C libraries or between the R6-R/24C and R6-
$\mathrm{R} / 16 \mathrm{C}$ libraries (Fig. 6B), showing that, in wild-type $N$. benthamiana plants, the increase of temperature enhances $5^{\prime}$-terminal nucleotide bias of CWMV siRNAs toward U.

\section{Silencing of NbRDR6 enhances the generation of siRNAs} from hotspots in the CWMV genome at low temperatures.

CWMV siRNAs in all siRNA libraries were distributed along the positive and negative strands of CWMV RNA1 (Figs. 7

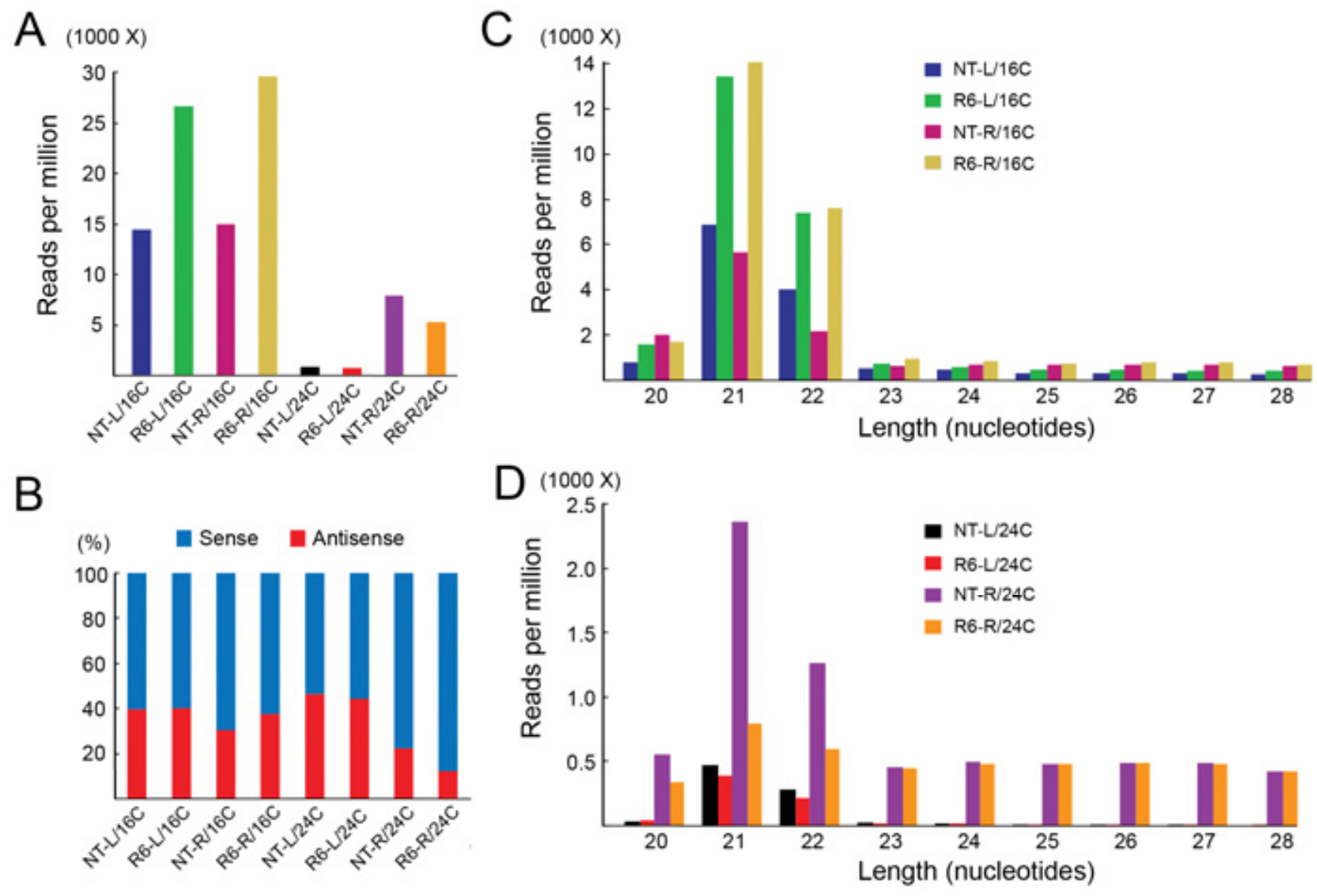

Fig. 5. Profiles of Chinese wheat mosaic virus (CWMV)-derived small interfering (si)RNAs captured by deep sequencing. A, Abundance of CWMV siRNAs derived from the eight libraries. B, Percentage of sense and antisense CWMV siRNAs. C and D, Size distribution of CWMV siRNAs. Libraries NT-L/16C and NT-R/16C are from upper leaves and roots, respectively, of CWMV-infected nontransgenic Nicotiana benthamiana plants grown at $16^{\circ} \mathrm{C}$ for 6 weeks; R6-L/16C and R6-R/16C are from upper leaves and roots, respectively, of CWMV-infected transgenic N. benthamiana plants silenced for RNA-dependent RNA polymerase $6\left(\mathrm{NbRDR} 6 \mathrm{i}\right.$ ) grown at $16^{\circ} \mathrm{C}$ for 6 weeks; NT-L/24C and NT-R/24C are from upper leaves and roots, respectively, of CWMV-infected nontransgenic $N$. benthamiana plants that were previously grown at $16^{\circ} \mathrm{C}$ for 6 weeks and then kept at $24^{\circ} \mathrm{C}$ for 1 week; and $\mathrm{R} 6-\mathrm{L} / 24 \mathrm{C}$ and $\mathrm{R} 6-\mathrm{R} / 24 \mathrm{C}$ are from upper leaves and roots, respectively, of CWMV-infected NbRDR6i plants that had similar treatment.
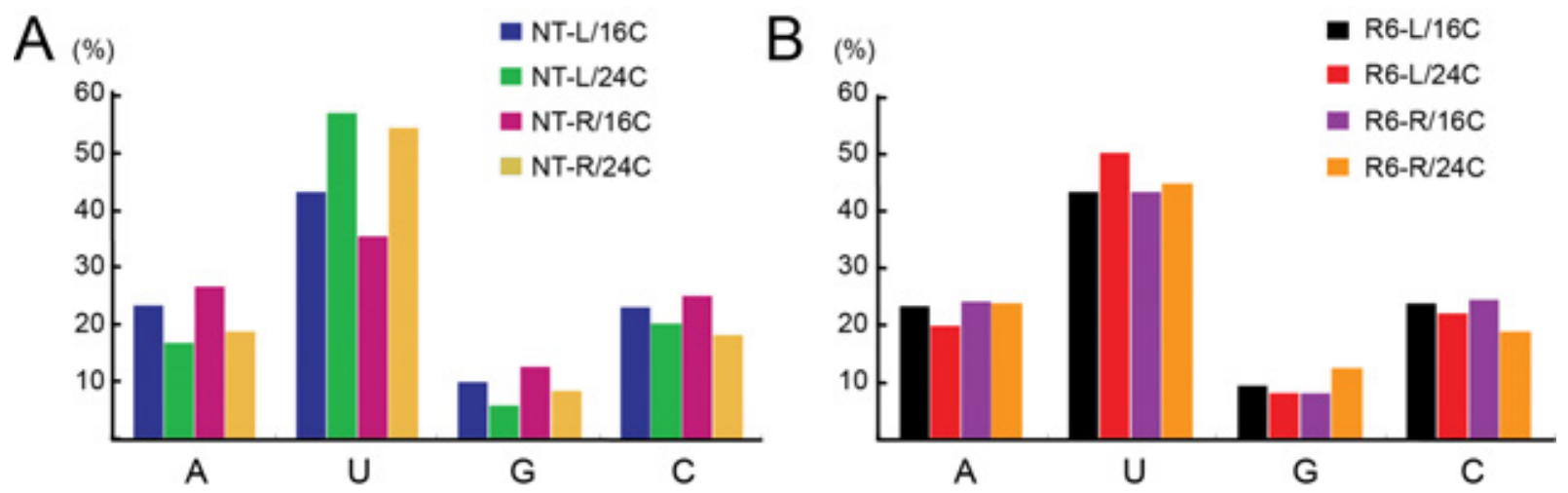

Fig. 6. Relative frequency of the $5^{\prime}$-terminal nucleotide of Chinese wheat mosaic virus (CWMV) small interfering (si)RNAs. A, CWMV siRNAs are derived from the nontransgenic Nicotiana benthamiana plants (Libraries NT-L/16C, NT-L/24C, NT-R/16C, and NT-R/24C). B, CWMV siRNAs are derived from the transgenic $N$. benthamiana plants silenced for RNA-dependent RNA polymerase 6 (Libraries R6-L/16C, R6-L/24C, R6-R/16C, and R6-R/24C). 
and 8) and RNA2 (Supplementary Figs. S2 and S3). Strikingly, there were numerous prominent siRNA hotspots in the R6-L/ 16C and R6-R/16C libraries for both RNA1 and RNA2, with the siRNA hotspots in the R6-R/16C library being much stronger and more frequent than in the R6-L/16C library (Fig. 7). In contrast, no such prominent siRNA hotspots were present in the NT-L/16C and NT-R/16C libraries (Fig. 7). This suggests that silencing of NbRDR6 stimulates the generation of viral siRNAs from hotspots in the CWMV genome. All of the siRNA hotspots consisted of 21- or 22-nt siRNAs, suggesting that, indeed, they are cleavage sites of DCL, presumably DCL4 or DCL2 (Aliyari and Ding 2009; Ding 2010). Most of the siRNA hotspots did not occur similarly on both genomic strands (asymmetrical), suggesting that they possibly originated from DCL-mediated processing of highly structured viral ssRNAs. However, we were unable to identify a clear relationship between the predicted RNA secondary structures and the siRNA hotspots using the online software RNAFold (data not shown).
The numbers of unique CWMV siRNAs (not identical in sequence to any other siRNAs) in the R6-L/16C library were markedly higher than in the NT-L/16C library whereas they were only slightly higher in R6-R/16C than in NT-R/16C (Supplementary Fig. S4). Taken together, these observations suggest that the increased frequency of siRNA in roots of NbRDR6i plants is not primarily due to an increase of the number of Dicer cleavage sites in the CWMV genome but, rather, is because more siRNAs are produced from hotspots. Some siRNA hotspots were also present in both NT-R/24C and $\mathrm{R} 6-\mathrm{R} / 24 \mathrm{C}$ libraries but hotspots in R6-R/24C appeared to be less prominent than those in NT-R/24C (Fig. 8), which is likely due to the lower numbers of 21- and 22-nt siRNAs (Fig. 5D). Thus, the increase in temperature moderately enhances the generation of CWMV siRNAs from hotspots in roots. Apparently, siRNAs from the negative strands of CWMV RNA1 were much less frequent in the R6-R/24C than in the NT-R/24C library (Fig. 8).

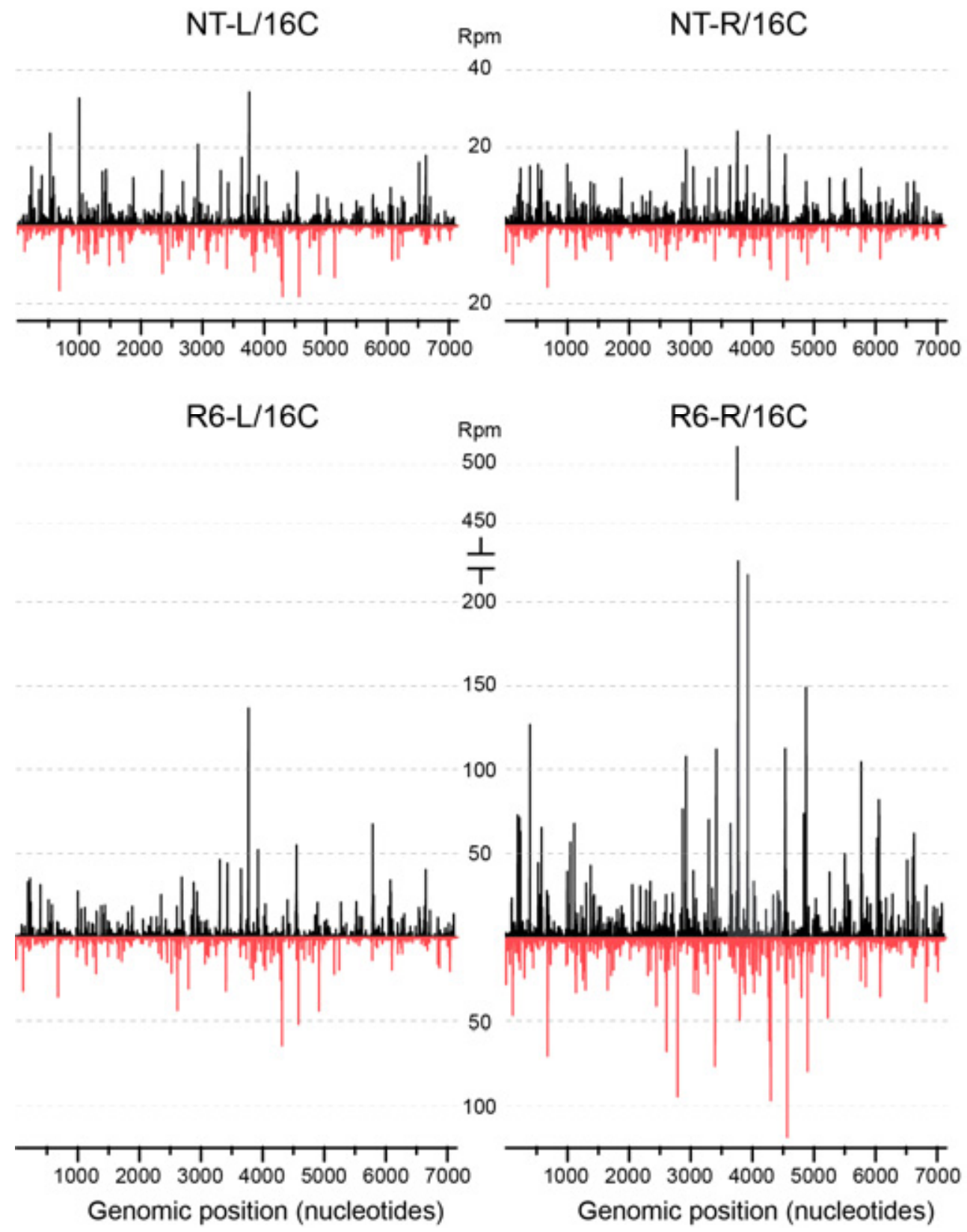

Fig. 7. Distribution of Chinese wheat mosaic virus small interfering (si)RNAs along the genomic RNA1 in infected plants grown throughout at $16^{\circ} \mathrm{C}$ (libraries NT-L/16C, NT-R/16C, R6-L/16C, and R6-R/16C). Black and gray peaks indicate viral siRNAs derived from the positive and negative genomic strands, respectively. Rpm: Reads per million. 


\section{DISCUSSION}

Because RNA silencing is an important antiviral defense in plants, we particularly focused in this study on the possibility that the strong inhibition of CWMV infection at higher temperatures is mediated by the activity of RNA silencing. In the co-infection experiment, PVY but not PVX infection rescued CWMV accumulation in leaves and roots at $24^{\circ} \mathrm{C}$ (Fig. $2 \mathrm{C}$ and D). Co-infection with PVY or other potyviruses commonly results in increased accumulation of the co-infecting virus (Syller 2012). Recently, PVY infection was also shown to increase viral RNA accumulation of a co-infecting virus in root tissue (Andika et al. 2012). HC-Pro encoded by potyviruses is a potent RNA-silencing suppressor that interferes with multiple steps in the RNA-silencing pathway (Anandalakshmi et al. 1998; Brigneti et al. 1998; Kasschau and Carrington 1998; Kasschau et al. 2003; Mallory et al. 2002) and it is responsible for the synergistic effect in viral mixed infections (Pruss et al. 1997; Shi et al. 1997; Vance et al. 1995). Thus, the strong RNA-silencing suppression conferred by PVY infection may facilitate CWMV accumulation at the higher temperature. Given that antiviral RNA-silencing defense is more effective at higher temperatures (Szittya et al. 2003; Zhang et al. 2012), it seems reasonable to propose that inhibition of CWMV multiplication at higher temperatures is due, in part, to the inability of CWMV to effectively suppress RNA silencing. Supporting this proposal, we recently showed that CWMV encodes a weak RNA-silencing suppressor (Sun et al. 2013). Notably, the ability of PVY to rescue CWMV accumulation was less potent in leaves than in roots (Fig. 2C). This difference may be related to the higher levels of RNA-silencing activity in leaves than roots, as previously suggested by several studies (Andika et al. 2005, 2006; De Wilde et al. 2001; Marjanac et al. 2009; Tomita et al. 2004). Furthermore, this may also explain why CWMV RNA accumulated much more abundantly in roots than in leaves (Fig. 3B). Nevertheless, our data do not rule out the possibility that other mechanisms besides RNA silencing also participate in the inhibition of CWMV accumulation at higher temperatures. For example, CWMV replication may be less optimal at higher temperatures, which is similar to that observed with SBWMV (Ohsato et al. 2003).

In previous studies, antiviral activity of RDR was only investigated in aerial tissues of plants. Our experiments provide novel evidence that the antiviral role of NbRDR6 in defense against CWMV infection differs between leaves and roots at both low and higher temperatures. At $16^{\circ} \mathrm{C}$, silencing of NbRDR6 enhanced CWMV RNA accumulation in leaves but not in roots (Fig. 3B). The notion that RNA-silencing activity is lower in roots than in leaves may provide an explanation for this observation. At low temperatures, where antiviral silencing in leaves is suboptimal, NbRDR6 is still able to limit CWMV accumulation; however, under these conditions, antiviral RNA-silencing activity in roots may be strongly diminished, leading to saturated levels of CWMV accumulation in
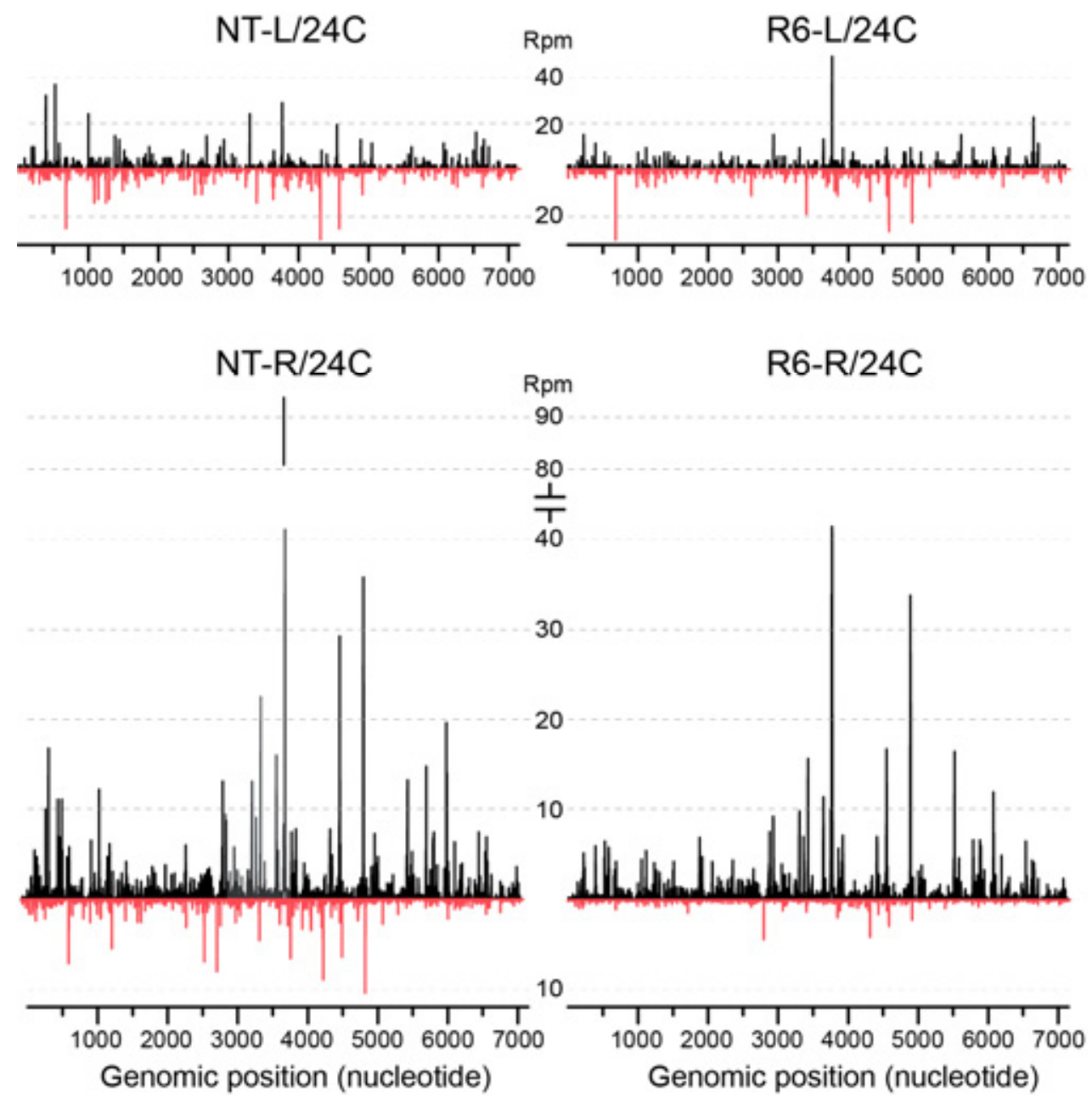

Fig. 8. Distribution of Chinese wheat mosaic virus small interfering (si)RNAs along the genomic RNA1 in infected plants shifted to $24^{\circ} \mathrm{C}$ for 1 week (libraries NT-L/24C, NT-R/24C, R6-L/24C, and R6-R/24C). Black and gray peaks indicate viral siRNAs derived from the positive and negative genomic strands, respectively. Rpm: Reads per million. 
the cells. Moreover, silencing of NbRDR6 also enhanced the efficiency of systemic spread of CWMV (Fig. 3A and C), which is similar to the observation that viral systemic spread of PVX carrying a green fluorescent protein is enhanced in NbRDR6i plants (Schwach et al. 2005). Therefore, our observation is consistent with the proposal that NbRDR6 is required for the cell to process silencing signals that spread from the initial sites of virus infection (Schwach et al. 2005).

At $16^{\circ} \mathrm{C}$, silencing of $N b R D R 6$ increased the abundance of CWMV siRNAs (Fig. 5), suggesting that the action of NbRDR6 to limit CWMV accumulation in leaves does not occur at the step of viral siRNA amplification. Thus, the increase of viral multiplication in NbRDR6i plants may provide more dsRNA substrates for viral siRNA production. In contrast to the situation in leaves, increased abundance of CWMV siRNA in roots is not apparently due to an increase in the numbers of DCL cleavage sites but mostly because more siRNAs are generated from hotspots in the CWMV genome (Fig. 7), suggesting that the downregulation of NbRDR6 may alter the preferential RNA substrates of DCL in roots. Because RDR and DCL activities are usually coupled, as in the case of RDR6 and DCL4 or DCL2 in Arabidopsis (Voinnet 2008), it is possible that, when NbRDR6 is silenced, DCL gain access to highly structured viral ssRNAs more efficiently. Interestingly, when the temperature was shifted to $24^{\circ} \mathrm{C}$, silencing of $N b R D R 6$ enabled CWMV to accumulate in roots but not in leaves (Fig. 4) and this was correlated with the reduced abundance of CWMV siRNA in roots but not in leaves, particularly the higher reduction in antisense than sense viral siRNAs (Fig. 5). These results strongly suggest that, at the higher temperature, NbRDR6 plays an essential role in inhibition of CWMV accumulation in roots through its function in amplifying CWMV siRNAs. NbRDR6 does not appear to be essential for generation of PVX-, Cymbidium ringspot virus (CymRSV)- and PSTVd-derived siRNAs in leaves (Di Serio et al. 2010; Schwach et al. 2005; Szittya et al. 2010), whereas rice RDR6 participates in generation of RSV siRNAs in leaves (Jiang et al. 2012). It is still unclear whether biosynthesis of viral siRNAs in $N$. benthamiana leaves does not require amplification or whether siRNA amplification is facilitated by redundant activities of other RDR orthologs. In Arabidopsis, biogenesis of viral siRNAs involves RDR1, RDR2, or RDR6, depending on the particular virus or whether the viral RNA-silencing suppressor is inactivated (Donaire et al. 2008; Garcia-Ruiz et al. 2010; Qi et al. 2009; Wang et al. 2010, 2011). N. benthamiana RDR1 is nonfunctional owing to the internal insertion that introduces a stop codon (Yang et al. 2004). Further studies are necessary to determine the RDR ortholog of $N$. benthamiana that is involved in biogenesis of viral siRNA and suppression of CWMV accumulation at higher temperatures.

Accumulation of viral siRNAs derived from CymRSV and Turnip crinkle virus (TCV) is drastically reduced at low temperatures ( 15 and $18^{\circ} \mathrm{C}$ for CymRSV and TCV, respectively) (Szittya et al. 2003; Zhang et al. 2012). It should be noted that the levels of viral RNA accumulations of CymRSV and TCV are also reduced at lower temperatures, which is likely due to the reduced level of viral replication (Szittya et al. 2003; Zhang et al. 2012). On the other hand, viruses belong to the genus Furovirus are well adapted to low temperatures, allowing for optimal viral genome replication at low temperatures (Ohsato et al. 2003). Our deep sequencing analysis also showed that abundant viral-derived siRNAs were generated in wheat plants infected with Wheat yellow mosaic virus (WYMV, genus Bymovirus) (L. Sun, unpublished data). WYMV is a soilborne virus that also infects wheat plants at low temperatures (Kühne 2009). Taken together with the results of CWMV siRNA analysis, our data suggest that viral siRNAs are, to some extent, generated at low temperatures as long as sufficient dsRNA substrates are produced during viral genome replication. However, it remains to be examined whether those viral siRNAs mediate the degradation of viral RNA targets as efficiently as at higher temperatures. The proportion of CWMV siRNAs with $5^{\prime}$-terminal nucleotide $\mathrm{U}$ is less at low than at higher temperatures (Fig. 6A). The small RNAs that have a 5'-terminal $U$ are the most efficiently loaded into AGO1, an AGO component required for the antiviral defense in plants (Mi et al. 2008; Montgomery et al. 2008; Wang et al. 2011). Thus, it is possible that a smaller proportion of CWMV siRNAs are incorporated into RISCs at lower than at higher temperatures.

\section{MATERIALS AND METHODS}

\section{Plant materials and virus isolates.}

'Zhengmai 9023' wheat plants were used for the inoculation experiment. The transgenic $N$. benthamiana line carrying a hairpin construct to silence NbRDR6 has been described previously (Schwach et al. 2005) and was kindly provided by D. Baulcombe (University of Cambridge, U.K.). Plants were kept in a greenhouse at 16 or $24^{\circ} \mathrm{C}$. Wheat plants infected with CWMV isolate Rongcheng (Yang et al. 2001) were obtained from Shandong Province, China and used as inoculum source for virus inoculation. PVY isolate $\mathrm{O}$ was maintained in $N$. benthamiana and used for inoculation. PVX was derived from the PVX vector pgR106 (Lu et al. 2003) (provided by D. Baulcombe) and agroinoculated into $N$. benthamiana plants by a toothpick method, as described previously (Lu et al. 2003).

\section{Virus inoculation.}

For mechanical leaf-inoculation, virus-infected leaves were ground in $0.1 \mathrm{M}$ phosphate buffer $(\mathrm{pH} 7.4$ ) and the sap was rubbed onto Carborundum-dusted leaves of wheat and N. benthamiana plants.

\section{ELISA and Western blot assay.}

Double-antibody sandwich ELISA was carried out following the method described previously (Andika et al. 2005) using polyclonal antibodies specific for CWMV CP. Absorbance values at $405 \mathrm{~nm}$ were recorded with a Spectramax M5 plate reader (Molecular Devices, Silicon Valley, CA, U.S.A.). Absorbance values above 0.3 were considered to be positive. Preparation of protein samples, sodium dodecyl sulfate polyacrylamide gel electrophoresis (PAGE), electroblotting, and immunodetection for Western blot analysis were carried out as described previously (Sun and Suzuki 2008). CWMV CP was detected using primary anti-CP $(1: 5,000)$ polyclonal serum and secondary polyclonal AP-conjugated goat anti-rabbit immunoglobulin G (IgG) (1:10,000) (Sigma-Aldrich, St. Louis). Actin was detected using primary $(1: 10,000)$ anti- $\beta$-actin polyclonal serum (Abcam, Pak Shek Kok, Hong Kong) and secondary $(1: 10,000)$ AP-conjugated goat anti-rabbit IgG (Sigma).

\section{RNA extraction, RT-PCR, and Northern blot analyses.}

Total RNAs were extracted from leaves and roots of $N$. benthamiana plants with Trizol (Invitrogen, San Diego, CA, U.S.A.) according to the manufacturer's instructions. For detection of CWMV RNA2 accumulation using RT-PCR, the CWMV CP coding region was amplified by RT-PCR using forward primer ' 5'-ATGGCCGTGAAATCTGGTTAT-3' and reverse primer 5'-TCAGCTCGAACCTTCCCACTT-3'. Firststrand cDNAs were synthesized using ReverTra Ace reverse transcriptase (Toyobo, Osaka, Japan) and amplified by PCR using Blend Tag DNA polymerase (Toyobo) according to the manufacturer's protocols. For Northern blot analysis, a digoxigenin (DIG)-labeled DNA probe specific for CWMV RNA2 
(nucleotides 325 to 855) was used. The probe was prepared using the PCR DIG Probe Synthesis Kit (Roche, Mannheim, Germany). Gel electrophoresis and blotting were carried out as described previously (Andika et al. 2005). Hybridization conditions and detection of mRNAs were as described in the DIG Application Manual supplied by Roche.

\section{Deep sequencing of small RNAs.}

The cDNAs of small RNA libraries were prepared by using the Illumina TrueSeq Small RNA Sample Preparation Kit (Illumina, San Diego, CA, U.S.A.). Briefly, the total RNA (5 $\mu \mathrm{g}$ ) was resolved on a denaturing $8 \%$ PAGE gel; then, the fraction containing the 18- to 30-nt small RNAs was purified. The isolated small RNAs were sequentially ligated to a $3^{\prime}$ adapter using T4 RNA ligase 2 (New England Biolabs, Ipswich, MA, U.S.A.) and a 5' adapter using T4 RNA ligase (New England Biolabs). The ligation products were reverse transcribed using SuperScript II Reverse Transcriptase (Life Technologies, Gaithersburg, MD, U.S.A.) and amplified with 12 PCR cycles. A $6 \%$ polyacrylamide gel was used to purify the amplification products, which were then sequenced using the Illumina HiSeq2000 (Illumina).

\section{Sequence analysis of small RNAs.}

The raw datasets derived from Illumina sequencing were computationally analyzed using Perl scripts. The pipeline analysis was as follows: small RNA reads without an identifiable linker were removed from raw reads, adaptor sequences were trimmed, and the reads of $>30$ or $<18 \mathrm{nt}$ were excluded from further analyses. To identify CWMV and NbRDR6 transgene siRNAs, processed reads from the eight libraries were mapped to CWMV RNA1 (National Center for Biotechnology Information [NCBI] accession number AJ271838), CWMV RNA2 (NCBI accession number AJ271839), and NbRDR6 (NCBI accession number DQ093875) using Bowtie software with one (for CWMV) or zero (for NbRDR6 transgene) mismatch allowed. Distribution maps of CWMV siRNAs along the RNA1 and -2 segments were generated using Origin software (OriginLab, Northampton, MA, U.S.A.).

\section{ACKNOWLEDGMENTS}

We thank D. Baulcombe for providing plant material, Y. Wu for providing PVY isolate, Z. Tan for experimental assistance, and M. Adams and H. Kondo for critically reading the manuscript. This study was funded by grants from the Project of New Varieties Genetically Modified Wheat of China (2008ZX08002-001) and China Agriculture Research System (CARS-3-1) from the Ministry of Agriculture of the P.R. China, the Project of Molecular Mechanism of Plant Defense to Pest and Disease (2012CB722504) from the Ministry of Science and Technology of the P.R. China, Modern Agricultural Biotechnology and Crop Disease Control from Key Subject Construction Program of Zhejiang Province, and the Program for Zhejiang Leading Team of Science and Technology Innovation and the Program for Leading Team of Agricultural Research and Innovation of Ministry of Agriculture, China.

\section{LITERATURE CITED}

Aliyari, R., and Ding, S. W. 2009. RNA-based viral immunity initiated by the Dicer family of host immune receptors. Immunol. Rev. 227:176188.

Anandalakshmi, R., Pruss, G. J., Ge, X., Marathe, R., Mallory, A. C., Smith, T. H., and Vance, V. B. 1998. A viral suppressor of gene silencing in plants. Proc. Natl. Acad. Sci. U.S.A. 95:13079-13084.

Andika, I. B., Kondo, H., and Tamada, T. 2005. Evidence that RNA silencing-mediated resistance to Beet necrotic yellow vein virus is less effective in roots than in leaves. Mol. Plant-Microbe Interact. 18:194-204.

Andika, I. B., Kondo, H., Rahim, M. D., and Tamada, T. 2006. Lower levels of transgene silencing in roots is associated with reduced DNA methylation levels at non-symmetrical sites but not at symmetrical sites. Plant Mol. Biol. 60:423-435.

Andika, I. B., Kondo, H., Nishiguchi, M., and Tamada, T. 2012. The cysteine-rich proteins of Beet necrotic yellow vein virus and Tobacco rattle virus contribute to efficient suppression of silencing in roots. J. Gen. Virol. 93:1841-1850.

Andika, I. B., Zheng, S., Tan, Z., Sun, L., Kondo, H., Zhou, X., and Chen, J. 2013. Endoplasmic reticulum export and vesicle formation of the movement protein of Chinese wheat mosaic virus are regulated by two transmembrane domains and depend on the secretory pathway. Virology 435:493-503.

Baulcombe, D. 2005. RNA silencing. Trends Biochem. Sci. 30:290-293.

Brigneti, G., Voinnet, O., Li, W.X., Ji, L. H., Ding, S. W., and Baulcombe, D. C. 1998. Viral pathogenicity determinants are suppressors of transgene silencing in Nicotiana benthamiana. EMBO (Eur. Mol. Biol. Organ.) J. 17:6739-6746.

Brunt, A. A., and Richards, K. E. 1989. Biology and molecular biology of furoviruses. Adv. Virus. Res. 36:1-32.

Chang, S. S., Zhang, Z., and Liu, Y. 2012. RNA interference pathways in fungi: Mechanisms and functions. Annu. Rev. Microbiol. 66:305-323.

Chellappan, P., Vanitharani, R., Ogbe, F., and Fauquet, C. M. 2005. Effect of temperature on geminivirus-induced RNA silencing in plants. Plant Physiol. 138:1828-1841.

Deleris, A., Gallego-Bartolome, J., Bao, J. S., Kasschau, K. D., Carrington, J. C., and Voinnet, O. 2006. Hierarchical action and inhibition of plant Dicer-like proteins in antiviral defense. Science 313:68-71.

De Wilde, C., Podevin, N., Windels, P., and Depicker, A. 2001. Silencing of antibody genes in plants with single-copy transgene inserts as a result of gene dosage effects. Mol. Genet. Genomics 265:647-653.

Diao, A., Chen, J., Ye, R., Zheng, T., Yu, S., Antoniw, J., and Adams, M. 1999. Complete sequence and genome properties of Chinese wheat mosaic virus, a new furovirus from China. J. Gen. Virol. 80:11411145 .

Diaz-Pendon, J. A., Li, F., Li, W. X., and Ding, S. W. 2007. Suppression of antiviral silencing by Cucumber mosaic virus $2 \mathrm{~b}$ protein in Arabidopsis is associated with drastically reduced accumulation of three classes of viral small interfering RNAs. Plant Cell 19:2053-2063.

Ding, S. W. 2010. RNA-based antiviral immunity. Nat. Rev. Immunol. 10:632-644.

Di Serio, F., Martinez de Alba, A. E., Navarro, B., Gisel, A., and Flores, R. 2010. RNA-dependent RNA polymerase 6 delays accumulation and precludes meristem invasion of a viroid that replicates in the nucleus. J. Virol. 84:2477-2489.

Donaire, L., Barajas, D., Martinez-Garcia, B., Martinez-Priego, L., Pagan, I., and Llave, C. 2008. Structural and genetic requirements for the biogenesis of Tobacco rattle virus-derived small interfering RNAs. J. Virol. 82:5167-5177.

García-Cano, E., Resende, R. O., Fernández-Muñoz, R., and Moriones, E. 2006. Synergistic interaction between Tomato chlorosis virus and Tomato spotted wilt virus results in breakdown of resistance in tomato. Phytopathology 96:1263-1269.

Garcia-Ruiz, H., Takeda, A., Chapman, E. J., Sullivan, C. M., Fahlgren, N., Brempelis, K. J., and Carrington, J. C. 2010. Arabidopsis RNA-dependent RNA polymerases and dicer-like proteins in antiviral defense and small interfering RNA biogenesis during Turnip mosaic virus infection. Plant Cell 22:481-496.

Garrett, K. A., Dendy, S. P., Frank, E. E., Rouse, M. N., and Travers, S. E. 2006. Climate change effects on plant disease: Genomes to ecosystems. Annu. Rev. Phytopathol. 44:489-509.

Goodin, M. M., Zaitlin, D., Naidu, R. A., and Lommel, S. A. 2008. Nicotiana benthamiana: Its history and future as a model for plant-pathogen interactions. Mol. Plant-Microbe Interact. 21:1015-1026.

Hull, R. 2002. Matthews's Plant Virology. Academic Press, U.K.

Jiang, L., Qian, D., Zheng, H., Meng, L. Y., Chen, J., Le, W. J., Zhou, T., Zhou, Y. J., Wei, C. H., and Li, Y. 2012. RNA-dependent RNA polymerase 6 of rice (Oryza sativa) plays role in host defense against negativestrand RNA virus, Rice stripe virus. Virus Res. 163:512-519.

Kalantidis, K., Psaradakis, S., Tabler, M., and Tsagris, M. 2002. The occurrence of CMV-specific short RNAs in transgenic tobacco expressing virus-derived double-stranded RNA is indicative of resistance to the virus. Mol. Plant-Microbe Interact. 15:826-833.

Kassanis, B. 1952. Some effects of high temperature on the susceptibility of plants to infection with viruses. Ann. Appl. Biol. 39:358-369.

Kasschau, K. D., and Carrington, J. C. 1998. A counterdefensive strategy of plant viruses: Suppression of posttranscriptional gene silencing. Cell 95:461-470.

Kasschau, K. D., Xie, Z., Allen, E., Llave, C., Chapman, E. J., Krizan, K. A., and Carrington, J. C. 2003. P1/HC-Pro, a viral suppressor of RNA silencing, interferes with Arabidopsis development and miRNA function. Dev. Cell 4:205-217. 
Kühne, T. 2009. Soil-borne viruses affecting cereals: Known for long but still a threat. Virus Res. 141:174-183.

Liu, J. Z., Richerson, K., and Nelson, R.S. 2009. Growth conditions for plant virus-host studies. Curr. Prot. Microbiol. Chapter 16, Unit 16A 11. Published online.

Lu, R., Malcuit, I., Moffett, P., Ruiz, M. T., Peart, J., Wu, A. J., Rathjen, J. P., Bendahmane, A., Day, L., and Baulcombe, D. C. 2003. High throughput virus-induced gene silencing implicates heat shock protein 90 in plant disease resistance. EMBO (Eur. Mol. Biol. Organ.) J. 22:5690-5699.

Mallory, A. C., Reinhart, B. J., Bartel, D., Vance, V. B., and Bowman, L. H. 2002. A viral suppressor of RNA silencing differentially regulates the accumulation of short interfering RNAs and micro-RNAs in tobacco. Proc. Natl. Acad. Sci. U.S.A. 99:15228-15233.

Marjanac, G., Karimi, M., Naudts, M., Beeckman, T., Depicker, A., and De Buck, S. 2009. Gene silencing induced by hairpin or inverted repeated sense transgenes varies among promoters and cell types. New Phytol. 184:851-864.

Merkling, S. H., and van Rij, R. P. 2012. Beyond RNAi: Antiviral defense strategies in Drosophila and mosquito. J. Insect. Physiol. 59:159-170.

Mi, S., Cai, T., Hu, Y., Chen, Y., Hodges, E., Ni, F., Wu, L., Li, S., Zhou, H., Long, C., Chen, S., Hannon, G. J., and Qi, Y. 2008. Sorting of small RNAs into Arabidopsis argonaute complexes is directed by the $5^{\prime}$ terminal nucleotide. Cell 133:116-127.

Mizumoto, H., Hikichi, Y., and Okuno, T. 2002. The 3'-untranslated region of RNA1 as a primary determinant of temperature sensitivity of Red clover necrotic mosaic virus Canadian strain. Virology 293:320-327.

Montgomery, T. A., Howell, M. D., Cuperus, J. T., Li, D., Hansen, J. E. Alexander, A. L., Chapman, E. J., Fahlgren, N., Allen, E., and Carrington, J. C. 2008. Specificity of ARGONAUTE7-miR390 interaction and dual functionality in TAS3 trans-acting siRNA formation. Cell 133:128-141.

Mourrain, P., Beclin, C., Elmayan, T., Feuerbach, F., Godon, C., Morel, J. B., Jouette, D., Lacombe, A. M., Nikic, S., Picault, N., Remoue, K., Sanial, M., Vo, T. A., and Vaucheret, H. 2000. Arabidopsis SGS2 and SGS3 genes are required for posttranscriptional gene silencing and natural virus resistance. Cell 101:533-542.

Ohsato, S., Miyanishi, M., and Shirako, Y. 2003. The optimal temperature for RNA replication in cells infected by Soil-borne wheat mosaic virus is $17^{\circ}$ C. J. Gen. Virol. 84:995-1000.

Pruss, G., Ge, X., Shi, X. M., Carrington, J. C., and Bowman Vance, V. 1997. Plant viral synergism: The potyviral genome encodes a broadrange pathogenicity enhancer that transactivates replication of heterologous viruses. Plant Cell 9:859-868.

Qi, X., Bao, F. S., and Xie, Z. 2009. Small RNA deep sequencing reveals role for Arabidopsis thaliana RNA-dependent RNA polymerases in viral siRNA biogenesis. PLoS One 4:e4971. Published online.

Qu, F. 2010. Antiviral role of plant-encoded RNA-dependent RNA polymerases revisited with deep sequencing of small interfering RNAs of virus origin. Mol. Plant-Microbe Interact. 23:1248-1252.

Qu, F., Ye, X., Hou, G., Sato, S., Clemente, T. E., and Morris, T. J. 2005. RDR6 has a broad-spectrum but temperature-dependent antiviral defense role in Nicotiana benthamiana. J. Virol. 79:15209-15217.

Roossinck, M. J. 1991. Temperature-sensitive replication of cucumber mosaic virus in muskmelon (Cucumis melo $\mathrm{cv}$. Iroquois), maps to RNA 1 of a slow strain. J. Gen. Virol. 72:1747-1750.

Schwach, F., Vaistij, F. E., Jones, L., and Baulcombe, D. C. 2005. An RNA-dependent RNA polymerase prevents meristem invasion by Potato virus $X$ and is required for the activity but not the production of a systemic silencing signal. Plant Physiol. 138:1842-1852.

Shi, X. M., Miller, H., Verchot, J., Carrington, J. C., and Vance, V. B.
1997. Mutations in the region encoding the central domain of helper component-proteinase (HC-Pro) eliminate Potato virus X/potyviral synergism. Virology 231:35-42.

Sun, L., and Suzuki, N. 2008. Intragenic rearrangements of a mycoreovirus induced by the multifunctional protein p29 encoded by the prototypic hypovirus CHV1-EP713. RNA 14:2557-2571.

Sun, L., Andika, I. B., Kondo, H., and Chen, J. 2013. Identification of the amino acid residues and domains in the cysteine-rich protein of Chinese wheat mosaic virus that are important for RNA silencing suppression and subcellular localization. Mol. Plant Pathol. 14:265-278.

Syller, J. 2012. Facilitative and antagonistic interactions between plant viruses in mixed infections. Mol. Plant Pathol. 13:204-216.

Szittya, G., Silhavy, D., Molnar, A., Havelda, Z., Lovas, A., Lakatos, L., Banfalvi, Z., and Burgyan, J. 2003. Low temperature inhibits RNA silencing-mediated defence by the control of siRNA generation. EMBO (Eur. Mol. Biol. Organ.) J. 22:633-640.

Szittya, G., Moxon, S., Pantaleo, V., Toth, G., Rusholme Pilcher, R. L., Moulton, V., Burgyan, J., and Dalmay, T. 2010. Structural and functional analysis of viral siRNAs. PLoS Pathog. 6:e1000838. Published online.

Tomita, R., Hamada, T., Horiguchi, G., Iba, K., and Kodama, H. 2004. Transgene overexpression with cognate small interfering RNA in tobacco. FEBS (Fed. Eur. Biochem. Soc.) Lett. 573:117-120.

Vance, V. B., Berger, P. H., Carrington, J. C., Hunt, A. G., and Shi, X. M. 1995. 5' Proximal potyviral sequences mediate potato virus X/potyviral synergistic disease in transgenic tobacco. Virology 206:583-590.

Voinnet, O. 2008. Use, tolerance and avoidance of amplified RNA silencing by plants. Trends Plant Sci. 13:317-328.

Wang, X. B., Wu, Q., Ito, T., Cillo, F., Li, W. X., Chen, X., Yu, J. L., and Ding, S. W. 2010. RNAi-mediated viral immunity requires amplification of virus-derived siRNAs in Arabidopsis thaliana. Proc. Natl. Acad. Sci. U.S.A. 107:484-489.

Wang, X. B., Jovel, J., Udomporn, P., Wang, Y., Wu, Q., Li, W. X., Gasciolli, V., Vaucheret, H., and Ding, S. W. 2011. The 21-nucleotide, but not 22nucleotide, viral secondary small interfering RNAs direct potent antiviral defense by two cooperative argonautes in Arabidopsis thaliana. Plant Cell 23:1625-1638.

Wang, Y., Bao, Z., Zhu, Y., and Hua, J. 2009. Analysis of temperature modulation of plant defense against biotrophic microbes. Mol. PlantMicrobe Interact. 22:498-506.

Xie, Z., Fan, B., Chen, C., and Chen, Z. 2001. An important role of an inducible RNA-dependent RNA polymerase in plant antiviral defense. Proc. Natl. Acad. Sci. U.S.A. 98:6516-6521.

Yang, J., Chen, J., Jiang, H., Zhao, Q., and Adams, M. J. 2001. Sequence of a second isolate of Chinese wheat mosaic furovirus. J. Phytopathol. 149:135-140

Yang, S. J., Carter, S. A., Cole, A. B., Cheng, N. H., and Nelson, R. S. 2004. A natural variant of a host RNA-dependent RNA polymerase is associated with increased susceptibility to viruses by Nicotiana benthamiana. Proc. Natl. Acad. Sci. U.S.A. 101:6297-6302.

Zhang, X., Singh, J., Li, D., and Qu, F. 2012. Temperature-dependent survival of Turnip crinkle virus-infected Arabidopsis plants relies on an RNA silencing-based defense that requires DCL2, AGO2, and HEN1. J. Virol. 86:6847-6854

\section{AUTHOR-RECOMMENDED INTERNET RESOURCES}

The RNA Institute The UNAFold Web Server: mfold.rna.albany.edu Johns Hopkins University Bowtie software: bowtie-bio.sourceforge.net 